\title{
Estimação do tamanho de parcela para experimento com cultura de tecidos em videira
}

\section{Estimation of plot size for experiments with tissue culture in grape}

\author{
Augusto Ramalho de Morais ${ }^{1 *}$; Aparecida Gomes de Araújo²; \\ Moacir Pasquali3; Ana Patrícia Bastos Peixoto ${ }^{4}$
}

\begin{abstract}
Resumo
O aprimoramento das técnicas experimentais do cultivo in vitro pode auxiliar em melhor identificação e multiplicação de materiais mais promissores. O objetivo desse trabalho foi a estimação do tamanho de parcelas (número de explantes) para micropropagação de videira in vitro. Foram conduzidos 15 ensaios de uniformidade formados pelas combinações de três porta-enxertos de videira com cinco diferentes meios de cultivo. Foram usados segmentos nodais com cerca $2,5 \mathrm{~cm}$ que foram excisados e inoculados. Após 90 dias de inoculação, foram feitas avaliações das variáveis: número de brotos, comprimento da parte aérea, a massa fresca da parte aérea e massa fresca de calos. Para cada ensaio, foram formados diversos tamanhos de parcelas, em que cada tubo, contendo um explante, foi considerado como uma unidade básica. Para a estimação do tamanho ótimo de parcela empregou-se o método da máxima curvatura modificado e as diferenças mínimas significativas entre médias foram obtidas pelo método de Hatheway. Os resultados mostraram que as estimativas do tamanho de parcela variaram de cinco (5) a 12 explantes (tubos) em acordo com a variável utilizada. Para as variáveis estudadas, o tamanho de parcela ótimo deve ser formado por 12 explantes.
\end{abstract}

Palavras-chave: Vitis sp., Coeficiente de variação, tamanho de amostra, precisão experimental, ensaio de uniformidade, planejamento experimental

\begin{abstract}
The improvement of experimental techniques of in vitro culture may provide better identification and multiplication of most promising materials. The aim of this study was to estimate the plot size (explants numbers) for in vitro micropropagation grape. 15 tests were conducted uniformity formed by combinations of three rootstock vine with five different culture media. Nodes segments were used with about $2.5 \mathrm{~cm}$, were excised and inoculated. After 90 days of inoculation, the variables shoot number, shoot length, shoot fresh weight, and fresh weight of callus were evaluated. For each assay, was simulated plots of differents sizes, with each tube containing one explant was considered as a basic unit. For estimation the optimum plot size we used the modified maximum curvature method and the least significant difference between means was obtained by the method of Hatheway. The results showed that the estimates of the plot size ranged from five (5) to 12 explants (tubes) in accordance with the variable used. For these variables, the optimal plot size should be formed by 12 explants.

Key words: Vitis $s p$., coefficient of variation, sample size, experimental precision, uniformity trial, planning experimental
\end{abstract}

${ }^{1}$ Eng $^{\mathrm{o}} \mathrm{Agr}^{\mathrm{o}}$, Prof. Associado do Dept ${ }^{\circ}$ de Ciências Exatas da Universidade Federal de Lavras, UFLA, Lavras, MG. Bolsista de produtividade do CNPq. E-mail: armorais@dex.ufla.br

2 Eng $^{\mathrm{a}}$ Agr ${ }^{\mathrm{a}}$, Pesquisadora, Dr ${ }^{\mathrm{a}}$ da Syngenta Seeds Ltda, Uberlândia, MG. E-mail: agaraujo@yahoo.com.br

${ }^{3}$ Eng $^{\mathrm{o}} \mathrm{Agr}^{\circ}$, Prof. Titular do Dept ${ }^{\circ}$ de Agricultura, UFLA, Lavras, MG. Bolsista de produtividade do CNPq. E-mail: mpasqual@ dag.ufla.br

${ }^{4}$ Eng $^{\mathrm{a}}$ Agr $^{\mathrm{a}}$, Prof ${ }^{\mathrm{a}}$ Adjunta do Dept ${ }^{\mathrm{o}}$ de Estatística, Universidade Estadual da Paraíba, UEPB, Campina Grande, PB. E-mail: anapatricia@cct.uepb.edu.br

* Autor para correspondência 


\section{Introdução}

A conservação e propagação de germoplasmas é caminho racional para consolidação de uma cultura, por permitir a preservação da variabilidade genética e possibilitar seu uso em programas de melhoramento genético e outras aplicações futuras.

A técnica de micropropagação da videira (Vittis $s p$ ) se destaca na obtenção de material vegetativo de boa qualidade fitossanitária (BIASI; PASSOS; POMMER, 1998; DZAZIO; BIASI; ZANATTE, 2002), rápida propagação (WETZSTEIN; MYERS, 1994) possibilitando a obtenção de plantas livres de vírus (PEIXOTO; PASQUAL, 1996; DZAZIO; BIASI; ZANATTE, 2002). Devido a crescente melhoria e necessidade de novas tecnologias, se torna necessários experimentos mais precisos.

Entre os fatores que afetam a qualidade dos resultados de um experimento, se destaca a unidade experimental. A utilização de tamanho adequado da parcela e planejamento adequado do experimento contribui com a obtenção de resultados com melhor precisão e qualidade. $\mathrm{O}$ uso de tamanho de parcela ótimo é um modo de se reduzir o erro experimental, sendo crucial para diferentes experimentos, pois, o que se procura detectar é a existência de diferenças significativas entre tratamentos testados, o que depende da redução do erro experimental (STEEL; TORRIE; DICKEY, 1997; BANZATTO; KRONKA, 2006).

Nos trabalhos com cultura de tecidos parece que não tem havido consenso com relação à utilização de um tamanho de parcela adequado e padronizado e, isso se repete com a cultura da videira. Este fato não é de se estranhar, pois o tamanho de parcela conveniente para determinada cultura, não deve ser generalizado, haja vista que variam de acordo com os fatores que afetam aquela cultura, como cultivar, local e característica avaliada, entre outros. No entanto, pode ser estendido para ambientes que sejam semelhantes. Para a cultura da videira não foram encontrados referências que tratassem especificamente desse assunto; parece que os experimentos são realizados usando-se tamanhos práticos de acordo com a disponibilidade de material ou experiência do pesquisador.

Para avaliar o efeito de concentrações de BAP no crescimento dos ápices meristemáticos e gemas axilares de porta-enxertos de videira, Biasi, Passos e Pommer (1998) usaram experimentos com quatro repetições e 10 frascos por parcela. Na propagação in vitro em videiras, Nali, Almeida e Melo (2005) utilizaram parcelas com seis plantas para avaliar aos 60 dias de cultivo as características comprimento da maior raiz primária (CRP), número de raízes primárias (NRP), número de raízes secundárias (NRS), comprimento do caule (CC), matéria fresca total (MFT) e matéria seca total (MST). $\mathrm{Na}$ micropropagação da variedade de videira "VR043-43", Machado et al. (2007) utilizaram o delineamento experimental em blocos ao acaso, com quatro repetições e para o isolamento dos segmentos nodais, foram utilizados 10 explantes por parcela. Também, Biondo et al. (2007) utilizaram parcelas constituídas por 10 explantes, por repetição, na micropropagação de Mandevilla velutina, utilizando o delineamento inteiramente casualizado, com três repetições.

Na micropropagação de porta-enxertos de videira realizada por Villa et al. (2006) e Villa et al. (2007a) as parcelas foram constituídas por 12 plântulas. Villa et al. (2009b) avaliando o crescimento in vitro de porta-enxertos de videira usaram o delineamento inteiramente casualizado, com quatro repetições, sendo os tratamentos dispostos em esquema fatorial, e as parcelas formadas com doze brotações. E, Dias et al. (2011) usaram parcelas constituídas por um frasco contendo três brotos (explantes).

O tamanho da parcela é de grande importância, pois estudos realizados com ensaios de uniformidade tem mostrado que a variabilidade por parcela tende a decrescer com o aumento da parcela; mas, a partir de determinado tamanho o ganho com precisão é muito pequeno (RAMALHO, FERREIRA; OLIVEIRA, 2012; STORCK et al., 2006). Assim, 
parcelas pequenas estão relacionadas ao uso de maior número de repetições e, consequentemente, aumentando a precisão, e parcelas grandes estão associadas à adoção de poucas repetições, o qual pode representar um risco para a precisão experimental (PETERSEN, 1994; PIMENTELGOMES, 2009). Conciliar essas duas situações não é tarefa fácil de ser realizada pelo pesquisador.

Dada a importância da conservação e propagação in vitro de espécies de videira e da carência de técnicas experimentais específicas para esse tipo de experimento, da necessidade de se obter um tamanho apropriado de parcela, com a finalidade de tornar os experimentos economicamente mais viáveis e possibilitar a comparação de tratamentos mais eficiente, o objetivo deste trabalho foi estimar o tamanho ótimo de parcelas para experimentos in vitro de videira, utilizando-se o método da máxima curvatura modificado.

\section{Material e Métodos}

Os dados utilizados para a realização deste trabalho foram provenientes de experimento conduzido no Laboratório de Cultura de Tecidos da Universidade Federal de Lavras, em Lavras, Minas Gerais, utilizando como material vegetal segmentos nodais de plantas de videira Vitis sp. Segmentos nodais com cerca $2,5 \mathrm{~cm}$ e 2 gemas axilares, oriundos de três porta-enxertos de videira ('R110', 'Kobber 5BB' - Vitis berlandieri x V. riparia e 'VR043-43' - $V$. vinifera $\times$ $V$. rotundifolia) pré-estabelecidos in vitro foram excisados e inoculados em cinco tipos de meio de cultura (Kc, MS, 1/2 MS, WPM e B5) e introduzidos em tubos de ensaio contendo 15 $\mathrm{mL}$ do meio de cultura. $\mathrm{O} \mathrm{pH}$ foi ajustado antes da adição de $7 \mathrm{~g} \mathrm{~L}^{-1}$ de ágar e da autoclavagem a $121^{\circ} \mathrm{C}$ e $1 \mathrm{~atm}$ por 20 minutos. Após a inoculação, os explantes foram mantidos em sala de crescimento a temperatura de $25 \pm 2^{\circ} \mathrm{C}$, irradiância de $35 \mu \mathrm{mol} \mathrm{m}{ }^{-2}$ $\mathrm{s}^{-1}$ e fotoperíodo de 16 horas, onde permaneceram nessas condições por 90 dias.

Ao final de 90 dias do cultivo in vitro, foram avaliados o número de brotos (NB), o comprimento da parte aérea (CPA), a massa fresca da parte aérea (PFPA) e massa fresca de calos (PFCA). A unidade experimental básica (UB) foi constituída por um (1) frasco de vidro com capacidade para $110 \mathrm{~cm}^{3}$, contendo $15 \mathrm{~mL}$ de meio de cultura e contendo um (1) explante.

Para estimação do tamanho de parcela, cada combinação de porta-enxerto com meio de cultura (tratamentos) foi considerado como um ensaio de uniformidade. Desse modo, para cada característica, utilizando-se as 40 unidades básicas, dispostas aleatoriamente, procedeu-se a formação de diferentes tamanhos de parcela (X), múltiplos do número de unidades básicas (UB), por meio da soma dos valores obtidos nas unidades básicas adjacentes. Foram simulados tamanhos de parcelas para $\mathrm{X}=$ $1,2,4,5,8,10$ e 20 unidades básicas (Tabela 1) utilizando-se modos distintos de se reunir os tubos adjacentes para se ter maior representatividade. Para cada valor de tamanho de parcela (X) foram estabelecidos os parâmetros: número de $\mathrm{UB}(\mathrm{N})$, variância entre parcelas de X UB $(\mathrm{Vx})$, variância por unidade básica $\left(\mathrm{Vr}=\mathrm{Vx} / \mathrm{X}^{2}\right)$ ou chamada de variância reduzida e coeficiente de variação $\left(\mathrm{CV}_{\mathrm{x}}\right)$ entre parcelas de X UB. 
Tabela 1. Tamanho da parcela $(\mathrm{X})$, tipos de agrupamentos dos tubos e número de parcelas totais para cada ensaio de uniformidade de explantes de videira (Vitis sp) aos 90 dias de conservação in vitro.

\begin{tabular}{cccc}
\hline Simulações & Tamanho $(\mathrm{X})$ & Tipo de agrupamento & Número de parcelas \\
\hline 1 & 1 & $1 \mathrm{x} 1$ & 40 \\
2 & 2 & $2 \mathrm{x} 1$ & 20 \\
3 & 2 & $1 \times 2$ & 20 \\
4 & 4 & $4 \times 1$ & 10 \\
5 & 4 & $1 \times 4$ & 10 \\
6 & 4 & $2 \times 2$ & 10 \\
9 & 5 & $1 \times 5$ & 8 \\
10 & 5 & $5 \times 1$ & 5 \\
11 & 8 & $8 \times 1$ & 5 \\
12 & 8 & $1 \times 8$ & 5 \\
13 & 8 & $2 \times 4$ & 5 \\
14 & 8 & $4 \times 2$ & 4 \\
15 & 10 & $5 \times 2$ & 4 \\
16 & 10 & $2 \times 5$ & 4 \\
17 & 10 & $1 \times 10$ & 4 \\
18 & 10 & $10 \times 1$ & 2 \\
20 & 20 & $4 \times 5$ & 2 \\
21 & 20 & $5 \times 4$ & 5 \\
\hline
\end{tabular}

Fonte: Elaboração dos autores.

O tamanho ótimo de parcela foi estimado utilizando-se o método da máxima curvatura modificado (LESSMAN; ATKINS, 1963). Nesse método, a medida de variabilidade dada pelo coeficiente de variação $\left(\mathrm{CV}_{\mathrm{x}}\right)$ e o tamanho da parcela com $\mathrm{X}$ unidades básicas é explicada pela relação $C V_{x}=\alpha X^{-\beta}$, na qual $\alpha$ e $\beta$ são os parâmetros a serem estimados. $\mathrm{O}$ tamanho ótimo da parcela $\left(\mathrm{X}_{0}\right)$ foi estimado pela expressão

$$
\mathrm{X}_{0}=\exp \left\{[1 /(2 \hat{\beta}+2)] \log \left[(\hat{\alpha} \hat{\beta})^{2}(2 \hat{\beta}+1) /(\hat{\hat{\beta}}+2)\right]\right\}
$$

na qual $\mathrm{X}_{0}$ é o valor da abscissa no ponto de máxima curvatura, o qual corresponde ao tamanho ótimo da parcela (MEIER; LESSMAN, 1971), $\hat{\alpha} \mathrm{e}$ $\hat{\beta}$ são os valores estimados dos parâmetros $\alpha$ e $\beta$.

$\mathrm{O}$ índice de variabilidade (b) do material experimental, conforme Smith (1938), foi estimado por meio da equação $\mathrm{V}_{\mathrm{r}}=\mathrm{V}_{\mathrm{l}} / \mathrm{X}^{\mathrm{b}}$, na qual b é uma medida do índice de variabilidade; $\mathrm{V}_{1}$ é a variância entre parcelas de uma (1) UB; X é o número de UB utilizados. Como os valores de $\mathrm{V}_{\mathrm{r}}$ tem diferentes números de graus de liberdade, pois envolvem diferentes tamanhos da parcela, a estimação dos valores de $\mathrm{V}_{1}$ e $\mathrm{b}$ foi ponderada pelos números de graus de liberdade associados a cada um dos tamanhos da parcela.

A diferença mínima significativa esperada entre duas médias $\mathrm{d}$, em porcentagem da média, foi calculada pela expressão: $d^{2}=2\left(t_{1}+t_{2}\right)^{2} C^{2} /$ $\left(r X^{b}\right)$, conforme Hatheway (1961), em que $t_{1}$ é o valor crítico da distribuição $t$ de Student no nível de significância de $5 \%$ e $\mathrm{t}_{2} \mathrm{o}$ valor tabelado de $\mathrm{t}$ de Student correspondente a 2(1-P), sendo $\mathrm{P}$ a probabilidade de se obter um resultado significativo, obtidos em função do número de graus de liberdade do erro experimental, $\mathrm{CV}$ é o coeficiente de variação, $r$ o número de repetições e $b$ o índice de variabilidade do material experimental. Para estimação da diferença d a ser detectada entre médias de dois tratamentos foram realizadas situações experimentais hipotéticas envolvendo combinações de diferentes coeficientes de variação $(\mathrm{CV}=10,15,20$ e $30 \%)$, números de repetição $(\mathrm{r}=$ $4,5$ e 6$)$, tamanhos de parcelas $(\mathrm{X}=2,4,6,8,10$ e 
12 explantes) e índice de variabilidade $\mathrm{b}=0,9055$ (valor médio das características). Considerouse experimentos no delineamento inteiramente casualizado com 5, 10 e 15 tratamentos; os valores de $t_{1}$ e $t_{2}$ foram obtidos para cada situação em função do número de graus de liberdade do erro experimental para os níveis de significância de 5\% e $40 \%$ respectivamente (considerando-se $\mathrm{P}=0,80$, o qual indica que se espera encontrar um resultado significativo em $80 \%$ dos casos).

Para exemplificar, seja um experimento com 15 tratamentos e cinco repetições; no delineamento inteiramente casualizado tem-se 60 números de graus de liberdade para o erro experimental; fixando-se a precisão experimental em $\mathrm{CV}=10 \%$, nível de significância de $5 \%\left(\mathrm{t}_{1}=\mathrm{t}_{(60 ; 5 \%)}=2,000\right)$ e a probabilidade de se obter diferenças significativas entre médias em $80 \%$ dos casos $\left(\mathrm{t}_{2}=\mathrm{t}_{(60 ; 40 \%)}=0,848\right)$. Substituindo esses valores, tem-se $\mathrm{d}^{2}=2(2,000+$ $0,848)^{2}(10)^{2} /\left(5.2^{0,9055}\right)=173,20$, que resulta em $\mathrm{d}=$ $13,16 \%$ ou $13 \%$ (Tabela 2 ).

As análises estatísticas foram realizadas com a utilização do programa computacional $\mathrm{R}$ Development Core Team (2013).

Tabela 2. Estimativas da diferença mínima significativa (\%) esperada para cada tamanho de parcela (X), em números de explantes, em relação a diferentes coeficientes de variação (C.V.) e número de repetições (r) para experimento inteiramente casualizado com 15,10 e 5 tratamentos e índice de variabilidade $b=0,905547$.

\begin{tabular}{|c|c|c|c|c|c|c|c|c|}
\hline \multirow{2}{*}{$\begin{array}{l}\text { Número de } \\
\text { Tratamentos }\end{array}$} & \multirow{2}{*}{$\begin{array}{l}\text { Coeficiente } \\
\text { de variação }\end{array}$} & \multirow{2}{*}{$\begin{array}{l}\text { Número de } \\
\text { repetição }\end{array}$} & \multicolumn{5}{|c|}{ Tamanho da parcela (X), em explantes } & \multirow[b]{2}{*}{12} \\
\hline & & & 2 & 4 & 6 & 8 & 10 & \\
\hline \multirow[t]{12}{*}{15} & 10 & 4 & 15 & 11 & 9 & 8 & 7 & 7 \\
\hline & & 5 & 13 & 10 & 8 & 7 & 6 & 6 \\
\hline & & 6 & 12 & 9 & 7 & 6 & 6 & 5 \\
\hline & 15 & 4 & 22 & 16 & 13 & 12 & 11 & 10 \\
\hline & & 5 & 20 & 14 & 12 & 11 & 9 & 9 \\
\hline & & 6 & 18 & 13 & 11 & 10 & 9 & 8 \\
\hline & 20 & 4 & 30 & 22 & 18 & 16 & 14 & 13 \\
\hline & & 5 & 26 & 19 & 16 & 14 & 13 & 12 \\
\hline & & 6 & 24 & 18 & 15 & 13 & 12 & 11 \\
\hline & 30 & 4 & 44 & 32 & 27 & 24 & 21 & 20 \\
\hline & & 5 & 39 & 29 & 24 & 21 & 19 & 17 \\
\hline & & 6 & 36 & 26 & 22 & 19 & 17 & 16 \\
\hline \multirow[t]{12}{*}{10} & 10 & 4 & 15 & 11 & 9 & 8 & 7 & 7 \\
\hline & & 5 & 13 & 10 & 8 & 7 & 6 & 6 \\
\hline & & 6 & 12 & 9 & 7 & 6 & 6 & 5 \\
\hline & 15 & 4 & 22 & 16 & 14 & 12 & 11 & 10 \\
\hline & & 5 & 20 & 14 & 12 & 11 & 10 & 9 \\
\hline & & 6 & 18 & 13 & 11 & 10 & 9 & 8 \\
\hline & 20 & 4 & 30 & 22 & 18 & 16 & 14 & 13 \\
\hline & & 5 & 26 & 19 & 16 & 14 & 13 & 12 \\
\hline & & 6 & 24 & 18 & 15 & 13 & 12 & 11 \\
\hline & 30 & 4 & 45 & 33 & 27 & 24 & 22 & 20 \\
\hline & & 5 & 40 & 29 & 24 & 21 & 19 & 18 \\
\hline & & 6 & 36 & 26 & 22 & 19 & 17 & 16 \\
\hline \multirow[t]{3}{*}{5} & 10 & 4 & 15 & 11 & 9 & 8 & 7 & 7 \\
\hline & & 5 & 14 & 10 & 8 & 7 & 6 & 6 \\
\hline & & 6 & 12 & 9 & 7 & 7 & 6 & 5 \\
\hline
\end{tabular}


continuação

\begin{tabular}{cccccccc}
15 & 4 & 23 & 17 & 14 & 12 & 11 & 10 \\
& 5 & 20 & 15 & 12 & 11 & 10 & 9 \\
20 & 6 & 18 & 13 & 11 & 10 & 9 & 8 \\
& 4 & 31 & 23 & 19 & 17 & 15 & 14 \\
30 & 5 & 27 & 20 & 17 & 14 & 13 & 12 \\
& 6 & 25 & 18 & 15 & 13 & 12 & 11 \\
& 4 & 46 & 34 & 28 & 25 & 22 & 21 \\
& 5 & 41 & 30 & 25 & 22 & 20 & 18 \\
& 6 & 37 & 27 & 22 & 20 & 18 & 16 \\
\hline
\end{tabular}

Fonte: Elaboração dos autores.

\section{Resultados e Discussão}

Observa-se que as estimativas dos tamanhos de parcela pelo método da máxima curvatura modificado variaram de cinco (5) UB para NB, CPA e PFPA até 12 UB para PFCA (Tabela 3). Estes resultados sugerem que de acordo com a variável utilizada pode-se ter diferentes tamanhos de parcelas. Para CPA as estimativas do tamanho de parcela apresentaram pequena variação, de cinco UB a sete (7) UB; para NB a variação foi de cinco a nove; para PFPA variou de cinco até nove UB e, para PFCA houve variação de sete UB a 12 UB. Estes resultados não estão diferentes daqueles utilizados por Villa et al. (2007a, 2007b), que na micropropagação de videira e amoreira-preta, usaram o delineamento inteiramente casualisado, com quatro repetições e com 12 brotações em cada. Também, parcelas constituídas por 12 tubos ou brotações foram utilizados por Villa et al. (2009a) no enraizamento de microestacas, por Villa et al (2009b) no crescimento in vitro de videira. Para micropropagação de mirtilo, Schuch et al. (2008) utilizaram experimento com quatro repetições, sendo que cada uma delas era constituída por um frasco com cinco explantes; e em Dias et al. (2011) a parcela experimental era representada por um frasco contendo três brotos (explantes). Resultados semelhantes aos apresentados na Tabela 3 foram encontrados por Peixoto, Faria e Morais (2011) na estimação do tamanho de parcela para experimento de conservação in vitro de maracujazeiro, no qual verificaram que os tamanhos de parcelas variaram com o método utilizado, encontrando-se parcelas formadas por seis explantes pelo modelo da regressão linear segmentado com platô e de dez explantes pelo modelo de regressão quadrática segmentado com platô.

No entanto, encontram-se tamanho de parcelas bem diferentes daqueles obtidos nesse trabalho, como em Oliveira, Pasqual e Paiva (1996) que usaram três tubos por parcela, na micropropagação de crisântemo `Orange reagen`; Faria et al. (2007) usaram parcela constituída por uma magenta contendo um explante no estabelecimento in vitro de espécies de maracujazeiro. Em Lima et al. (2008), cada tratamento foi repetido 20 vezes e, cada parcela foi constituída por um tubo, cada um contendo um explante por tubo, para indução de calos em segmentos de Croton urucurana Baill e, para multiplicação in vitro de amoreira-preta, Villa et al. (2008) usaram parcela formada por três tubos de ensaio e cada tubo contendo um explante.

A utilização de parcelas pequenas, como aquelas formadas por um explante, podem comprometer as inferências que são feitas posteriormente com base naqueles resultados, pois a confiabilidade e a qualidade dos dados obtidos são prejudicadas. Com isso, sugere-se a utilização de parcelas que tenham uma constituição adequada para cada tipo de experimento. Para experimentos em que irão ser avaliadas variáveis como CPA, pode-se observar pelo valor médio que o tamanho mínimo de parcela deve ser de ao menos seis (6) explantes por parcela. 
Também, pode-se verificar que maior variabilidade ocorreu com o PFCA, para a qual se exige um tamanho ótimo de 12 explantes, ou no mínimo um tamanho médio das características de nove (9) explantes.

Esperava-se que as estimativas dos tamanhos de parcelas não se diferissem muito de um ensaio para o outro, como ocorreu com NB e PCA, o que possibilita estimar um tamanho de parcela médio para todos os tratamentos, aqui de seis explantes ou um tamanho ótimo de oito explantes, pelo maior valor. Este fato já não ocorreu para PFPA e
PFCA que apresentaram maior amplitude, os quais necessitam de uma parcela maior. Como os ensaios foram realizados em laboratório, no qual se espera que as condições ambientais sejam homogêneas e controladas, o fato de se ter diferentes tamanhos de parcelas, provavelmente seja devido ao efeito dos próprios tratamentos ou das características avaliadas. Conforme relatam Paranaíba, Ferreira e Morais (2009), o método da máxima curvatura, às vezes, subestima o tamanho da parcela. Desse modo, para se ter uma qualidade melhor para todos os dados a ser obtidos, sugere-se utilizar o maior tamanho de parcela.

Tabela 3. Estimativas do tamanho de parcela $\left(\mathrm{X}_{0}\right)$, em números de explantes ou de frascos em relação aos diferentes ensaios (ou tratamentos) de uniformidade, para as características número de brotos (NB), comprimento da parte aérea (CPA), massa fresca da parte aérea (PFPA) e massa fresca de calos (PFCA) em experimento de micropropagação de videira.

\begin{tabular}{cccccc}
\hline \multirow{2}{*}{ Ensaio } & \multicolumn{2}{c}{ Característica } & \multirow{2}{*}{ Média } \\
\cline { 2 - 4 } & NB & CPA & PFPA & PFCA & \\
\hline 1 & 5,1 & 5,0 & 4,8 & 6,6 & 5,4 \\
2 & 5,2 & 5,2 & 5,6 & 7,6 & 5,9 \\
3 & 4,6 & 4,9 & 5,8 & 8,1 & 5,8 \\
4 & 4,9 & 4,7 & 5,9 & 6,2 & 5,4 \\
5 & 6,0 & 5,8 & 5,5 & 7,3 & 6,1 \\
6 & 7,8 & 5,7 & 8,3 & 11,0 & 8,2 \\
7 & 4,6 & 4,9 & 5,6 & 6,4 & 5,4 \\
8 & 5,3 & 4,7 & 6,8 & 6,6 & 5,8 \\
9 & 6,0 & 6,2 & 7,7 & 7,9 & 6,9 \\
10 & 7,0 & 5,9 & 7,4 & 8,5 & 7,2 \\
11 & 6,4 & 6,1 & 9,0 & 8,9 & 7,6 \\
12 & 6,9 & 6,6 & 8,1 & 11,5 & 8,3 \\
13 & 6,3 & 6,4 & 7,1 & 7,6 & 6,8 \\
14 & 5,5 & 6,4 & 7,0 & 6,9 & 6,4 \\
15 & 8,4 & 4,9 & 6,4 & 12,0 & 8,0 \\
\hline Média & $6,0(1,14)^{1}$ & $5,6(0,69)$ & $6,7(1,21)$ & $8,2(1,95)$ & $6,6(1,24)$ \\
\hline
\end{tabular}

${ }^{1}$ Valor entre parêntesis é o erro padrão para os tamanhos de parcelas.

Fonte: Elaboração dos autores.

Na determinação do ponto de máxima curvatura $\mathrm{X}_{0}$, destaca-se ainda que, na região superior ao ponto de máxima curvatura ainda pode ocorrer decréscimo nos valores do coeficiente de variação com o aumento no tamanho da parcela. No entanto, essa redução no coeficiente de variação é muito pequena em relação ao aumento no tamanho da parcela. Nesse caso, o ganho de incremento na precisão experimental não é compensatório. Mesmo assim, em casos como este, Henriques Neto et al. (2004) elucidam que o valor da abscissa no ponto de máxima curvatura deve ser interpretado como 
um limite inferior de tamanho de parcela, em vez de tamanho ótimo.

Os valores do índice de variabilidade (b) foram maiores para as variáveis PFPA e PFCA, em que o $\mathrm{b}$ foi em média 0,95 , enquanto que para as variáveis NB e CPA foi em média 0,86 (Tabela 4). Estes valores indicam baixa correlação entre as unidades adjacentes e elevada heterogeneidade entre as parcelas adjacentes. Este fato pode ser atribuído ao modo como as observações são coletadas em cada tubo de ensaio, haja vista que de um tubo para outro não se tem o princípio de continuidade, pois os valores de um tubo para outro são independentes. Como polo de comparação, dado que não se encontrou informações desse tipo para experimentos em laboratórios, em experimentos de campo quando o valor de b se aproxima de 1 , o aumento no tamanho da parcela é eficiente na melhoria da precisão em uma área experimental (LIN; BINNS, 1984; LEILAH; AL-KHTEED, 2007). Portanto, maior atenção deve ser dada no planejamento experimental, pois em experimentos conduzidos com tubos de ensaio é esperado se ter valores altos de $b$, próximos de 1 .

Tabela 4. Estimativas dos parâmetros do modelo $\mathrm{Vr}=\mathrm{V}_{1} / \mathrm{X}^{\mathrm{b}}$, respectivos erros padrão assintóticos, na média dos 15 ensaios, para as características número de brotos (NB), comprimento da parte aérea (CPA), massa fresca da parte aérea (PFPA) e massa fresca de calos (PFCA) em experimento de micropropagação de videira.

\begin{tabular}{cccccc}
\hline \multirow{2}{*}{ Parâmetro } & \multicolumn{4}{c}{ Característica } & \multirow{2}{*}{ Média } \\
\cline { 2 - 5 } & $\mathrm{NB}$ & $\mathrm{CPA}$ & PFPA & PFCA & \\
\hline $\mathrm{V}_{1}$ & 15,5626 & 5,6578 & 0,006755 & 0,054958 & - \\
& $(0,4896)$ & $(0,3243)$ & $(0,000239)$ & $(0,002841)$ & - \\
$\mathrm{b}$ & 0,87762 & 0,8439 & 0,933641 & 0,967026 & 0,905547 \\
& $(0,0319)$ & $(0,0560)$ & $(0,03838)$ & $(0,058083)$ & $(0,046091)$ \\
\hline
\end{tabular}

Fonte: Elaboração dos autores.

Apresentam-se na Tabela 2, valores das estimativas da diferença mínima significativa d, em porcentagem, que se pode detectar ou comprovar, no nível de 5\% de probabilidade, em experimentos inteiramente casualizados, baseadas em diferentes níveis fixados de coeficiente de variação. Ela simula situações experimentais de prováveis ocorrências. Verifica-se que, na medida em que se aumenta o $\mathrm{CV}$, diminui a sensibilidade da diferença mínima significativa. Ilustrando, verifica-se que, com 15 tratamentos e quatro repetições e tamanho de parcela de 12 explantes, um CV de $10 \%$ permite detectar diferenças de 7\% entre os tratamentos; já, para um CV de $20 \%$ detectará diferenças de $13 \%$ e CV de $30 \%$ somente diferenças de $20 \%$ ou mais.

O número de tratamentos em geral não afetou os valores de d, pequenas variações foram observadas; como exemplo, no caso de $\mathrm{CV}=15 \%$ e quatro repetições, os valores de d variaram de $22 \%$, com 15 tratamentos, para $23 \%$ no caso de cinco tratamentos (Tabela 2). Para um mesmo CV o aumento do número de repetições torna a diferença mínima significativa mais sensível, conforme se observa para a situação em que se tem 10 tratamentos, CV de $20 \%$ e tamanho de parcela de 12 explantes; nesse caso, se utilizar quatro repetições a diferença mínima significativa detectável entre dois tratamentos é de $13 \%$; entretanto, se usar de seis repetições esta diferença reduz para $11 \%$. Assim, com incremento do número de repetições existe ganho de precisão, mas o número de tratamentos teve pouco efeito na melhoria da precisão experimental.

Com relação a influência do tamanho da parcela sobre d, verificou-se que a medida que se aumentou o tamanho da parcela houve incremento na sensibilidade da diferença mínima significativa. 
Para uma situação que se tem CV de $15 \%, 10$ tratamentos e quatro repetições, em se usar parcelas formadas por dois explantes detectam-se diferenças mínimas entre dois tratamentos de $22 \%$; mas se utilizar 12 explantes detectará diferença de $10 \%$. Com o incremento no tamanho da parcela ocorre uma redução na diferença a ser detectada entre tratamentos.

Constata-se que o aumento no tamanho da parcela é uma estratégia eficiente para aumentar a precisão de experimentos; conforme as estimativas da diferença mínima significativa entre médias (d) que, em todas as combinações de CV e número de repetições, reduziram seus valores com o aumento no tamanho da parcela (Tabela 2). Os valores de d sugerem que se deve buscar um planejamento experimental de modo que a precisão seja alta, com menores valores de CV e de d. Como ilustração, para se planejar um experimento com 10 tratamentos, CV de $10 \%$ e usando-se uma parcela pequena, com dois explantes, somente consegue-se detectar diferenças entre tratamentos maiores do que $12 \%$; já, com parcelas formadas por 12 explantes, consegue-se detectar pequenas diferenças entre os tratamentos, da ordem de $5 \%$. Caso o CV for maior, como um experimento com menor precisão, por exemplo, $\mathrm{CV}=30 \%$, somente seriam detectadas diferenças mínimas significativas iguais ou maiores que $16 \%$ da média, em se usar parcelas formadas por 12 explantes e seis repetições. Como em uma pesquisa, geralmente se quer identificar se dois tratamentos são diferentes, sugerindo que pequenas diferenças devem ser detectadas, as estimativas de d, Tabela 2 , auxiliam no planejamento experimental.

A caracterização adequada da parcela confere maior precisão, e endossa a inferência dos resultados, pois, segundo Donato et al. (2008), independentemente dos objetivos dos experimentos, o que se procura detectar é a existência de diferenças significativas entre tratamentos testados. Caso se queira conduzir um experimento com 10 tratamentos no qual se pretende detectar diferenças de $10 \%$ entre médias de tratamentos, isto poderá ser possível, com o uso de seis repetições e oito explantes por parcela, em experimento com precisão (CV) de 15\%. Caso o CV seja maior do que $15 \%$ e a parcela menor do que 12 explantes, essa diferença dificilmente será detectada.

\section{Conclusões}

O tamanho de parcela ótimo deve ser formado por 12 explantes, pois satisfaz a todas variáveis.

$\mathrm{O}$ número de tratamentos não afeta os valores das diferenças entre médias de tratamentos.

Utilizando-se 12 explantes por parcela, em experimento com precisão de $\mathrm{CV}=15 \%$, esperase detectar diferenças de $10 \%$ e $8 \%$ entre médias de tratamentos com quatro a seis repetições, respectivamente.

\section{Agradecimentos}

Ao CNPq e à FAPEMIG pelo apoio financeiro no desenvolvimento da pesquisa e bolsa concedida.

\section{Referências}

BANZATTO, D. A.; KRONKA, S. N. Experimentação agrícola. 4. ed. Jaboticabal: Funep, 2006. 244 p.

BIASI, L. A.; PASSOS, I. R. S.; POMMER, C. V. Micropropagação do porta-enxerto de videira Jales. Pesquisa Agropecuária Brasileira, Brasília, v. 33, n. 10, p. 1587-1594, out. 1998.

BIONDO, R.; SOUZA, A. V.; BERTONI, B. W.; SOARES, A. M.; FRANÇA, S. C.; PEREIRA, A. M. $\mathrm{S}$. Micropropagation, seed propagation and germplasm bank of Mandevilla velutina (Mart.) Woodson. Scientia agricola, Piracicaba, v. 64, n. 3, p. 263-268, 2007.

DIAS, M. M.; PASQUAL, M.; ARAÚJO, A. G.; SANTOS, V. A.; OLIVEIRA, A. C.; RODRIGUES, V. A. Concentrações de reguladores vegetais no estiolamento in vitro de ananás do campo. Semina. Ciências Agrárias. Londrina, v. 32, n. 2, p. 513-520, abr./jun. 2011. 
DONATO, S. L. R.; SIQUEIRA, D. L.; SILVA, S. O.; CECON, P. R.; SILVA, J. A.; SALOMÃO, L. C. C. Estimativas de tamanho de parcelas para avaliação de descritores fenotípicos em bananeira. Pesquisa Agropecuária Brasileira, Brasília, v. 43, n. 8, p. 957-969, 2008.

DZAZIO, P. M.; BIASI, L. A.; ZANATTE, F. Micropropagação do porta-enxerto de videira "420-A". Revista Brasileira de Fruticultura, Jaboticabal, v. 24, n. 3, p. 759-764, 2002.

FARIA, G. A.; COSTA, M. A. P. C.; LEDO, C. A. S.; JANGHANS, T. G.; SOUZA, A. S.; CUNHA, M. A. P. Meio de cultura e tipo de explante no estabelecimento in vitro de espécies de maracujazeiro. Bragantia, Campinas, v. 66, n. 4, p. 535-543, 2007.

HATHEWAY, W. H. Convenient plot size. Agronomy Journal, Madison, v. 53, n. 4, p. 279-280, 1961.

HENRIQUES NETO, D.; SEDIYAMA, T.; SOUZA, M. A.; CECON, P. R.; TAMANAKA, C. H.; SEDIYAMA, M. A. N.; VIANA, A. E. S. Tamanho de parcelas em experimentos com trigo irrigado sob plantio direto e convencional. Pesquisa Agropecuária Brasileira, Brasília, v. 39, n. 6, p. 517-524, jun. 2004.

LEILAH, A. A.; AL-KHATEEB, S. A. Convenient quadratic size, shape and number in the desert rangeland of Saudi Arabia. Pakistan Journal of Agricultural Research, Islamabad, v. 20, n. 1-2, p. 62-70, 2007.

LESSMAN, K. J.; ATKINS, R. E. Optimum plot size and relative efficiency of lattice designs for grain sorghum yield test. Crop Science, Madison, v. 3, n. 6, p. 477-481, 1963.

LIMA, E. C.; PAIVA, R.; NOGUEIRA, R. C.; SOARES, F. P.; EMRICH, E. B.; SILVA, A. A. N. Callus induction in leaf segments of Croton urucurana Baill. Ciência e Agrotecnologia, Lavras, v. 32, n. 1, p. 17-22, 2008.

LIN, C. S.; BINNS, M. R. Working rules for determining the plot size and numbers of plots per block in field experiment. Journal of Agricultural Science, Cambridge, v. 103, n. 1, p. 11-15, 1984.

MACHADO, M. P.; BIASI, L. A.; RITTER, M.; RIBAS, L. L. F.; KOEHLER, H. S.; ZANETTE, F. Meios de cultura na micropropagação do porta-enxerto de videira "VR043-43" (Vitis vinifera x Vitis rotundifolia). Ciência Rural, Santa Maria, v. 37, n. 1, p. 277-280, 2007.

MEIER, V. D.; LESSMAN, K. J. Estimation of optimum field plot shape and size for testing yield in Crambe abyssinica Hochst. Crop Science, Madison, v. 11, n. 5, p. 648-650, 1971.
NALI, L. R.; ALMEIDA, W. A. B.; MELO, N. F. Propagação in vitro em videiras. Magistra, Cruz das Almas, v. 17, n. 2, p. 96-100, 2005.

OLIVEIRA, P. D.; PASQUAL, M.; PAIVA, R. Efeito de diferentes concentrações do meio MS, nitrogênio e sacarose na micropropagação de crisântemo 'Orange reagen`. Bragantia, Campinas, v. 55, n. 1, p. 9-18, 1996.

PARANAÍBA, P. F.; FERREIRA, D. F.; MORAIS, A. R. Tamanho ótimo de parcelas experimentais: proposição de métodos de estimação. Revista Brasileira de Biometria, São Paulo, v. 27, n. 2, p. 255-268, 2009.

PEIXOTO, A. P. B.; FARIA, G. A.; MORAIS, A. R. Modelos de regressão com platô na estimativa do tamanho de parcelas em experimento de conservação in vitro de maracujazeiro. Ciência Rural, Santa Maria, v. 41, n. 11, p. 1907-1913, 2011.

PEIXOTO, P. H. P.; PASQUAL, M. Influência da origem dos explantes na multiplicação e no enraizamento in vitro de porta-enxertos de videira. Ciência e Agrotecnologia, Lavras, v. 20, n. 3, p. 293-300, 1996.

PETERSEN, R. G. Agricultural field experiments: design and analysis. New York: Marcel Dekker, 1994. 409 p.

PIMENTEL-GOMES, F. Curso de estatística experimental. 15. ed. Piracicaba: Fealq, 2009. 464 p.

R DEVELOPMENT CORE TEAM. $R$ : A language and environment for statistical computing. Vienna, Austria: R Foundation for Statistical Computing, 2013. Disponível em: <http://www.R-project.org $>$. Acesso em: 12 mar. 2013.

RAMALHO, M. A. P.; FERREIRA, D. F.; OLIVEIRA, A. C. Experimentação em genética e melhoramento de plantas. Lavras: Editora UFLA, 2012. 303 p.

SCHUCH, M. W.; DAMIANI, C. R.; SILVA, L. C.; ERIG, A. C. Micropropagação como técnica de rejuvenescimento em mirtilo (Vaccinium ashei Reade) cultivar Climax. Ciência e Agrotecnologia, Lavras, v. 32, n. 3, p. 814-820, 2008.

SMITH, H. F. An empirical law describing heterogeneity in the yields of agricultural crops. Journal of Agricultural Science, Cambridge, v. 28, n. 1, p. 1-23, 1938.

STEEL, R. G. D.; TORRIE, J. H.; DICKEY, D. A. Principles and procedures of statistics: a biometrical approach. 3. ed. New York: McGraw-Hill, 1997. 666 p.

STORCK, L.; GARCIA, D. C.; LOPES, S. J.; ESTEFANEL, V. Experimentação vegetal. 2. ed. Santa Maria: Ed. da UFSM, 2006. 198 p. 
VILLA, F.; PASQUAL, M.; PIO, L. A. S.; ASSIS, F. A. Multiplicação in vitro de porta-enxerto de videira em variações do meio MS. Acta Scientiarium. Agronomy., Maringá, v. 28, n. 3, p. 345-349, july./sept. 2006.

VILLA, F.; PASQUAL, M.; PIO, L. A. S.; RIBEIRO, M. N. O.; ARAÚJO, A. G.; PEREIRA, A. R. Efeito de diferentes concentrações de nitrato de cálcio e cloreto de potássio na micropropagação de dois porta-enxertos de videira. Revista Ceres, Viçosa, v. 54, n. 314, p. 20-25, $2007 \mathrm{a}$.

VILLA, F.; PASQUAL, M.; PIO, L. A. S.; TEODORO, G. S. Cloreto de sódio e ácido naftalenoacético no enraizamento de microestacas de aroeira-preta cv. Brazos in vitro. Ciência e Agrotecnologia, Lavras, v. 33, p. 18191824, 2009a. Especial.

VILLA, F.; PASQUAL, M.; PIO, L. A. S.; TEODORO, G. S.; MIYATA, L. Y. Cloreto de potássio e fosfato de sódio na multiplicação in vitro de amoreira-preta cv. Tupi. Ciência e Agrotecnologia, Lavras, v. 32, n. 1, p. 37-41, 2008.
VILLA, F.; PASQUAL, M.; RIBEIRO, M. N. O. R.; FERREIRA, E. A.; PEREIRA, A. R.; ARAÚJO, A. G. Fosfato de sódio e cloreto de potássio na micropropagação de videira e amoreira-preta. Acta Scientiarium. Agronomy, Maringá, v. 29, n. 4, p. 541-547, 2007 b.

VILLA, F.; PASQUAL, M.; RODRIGUES, F. A.; SOUZA, A. G.; REZENDE, J. C. Efeito do sulfato de adenina e de 6-benzillaminopurina no crescimento in vitro de porta-enxertos de videira. Ciência e Técnica Vitivinícula, Dois Portos, v. 24, n. 1, p. 41-46. 2009b.

WETZSTEIN, H. Y.; MYERS, S. C. Vegetative and yield component characteristics of micropropagated muscadine grape (Vitis rotundifolia Michx.). The Journal of Horticultural Science \& Biotechnology, Ashford, v. 69, n. 4, p. 747-753, 1994. 
